\title{
Erratum to: Ferrocenyl building block constructing porous organic polymer for gas capture and methyl violet adsorption
}

HUANG Jing (黄晶) $)^{1,3}$, TAN Zhi-qiang(谭志强) $)^{1,2}$, SU Hui-min(苏惠敏 $)^{1,2}$, GUO Yi-wen(郭翼雯 $)^{1,2}$, LIU Huan(刘欢) ${ }^{1,2}$, LIAO Bo(廖博) $)^{1,2}$, LIU Qing-quan(刘清泉) ${ }^{1,2,3}$

1. Schoolof Materials Science and Engineering, Hunan University of Science and Technology, Xiangtan 411201, China;

2. Hunan Provincial Key Lab of Advanced Materials for New Energy Storage and Conversion, Xiangtan 411201, China;

3. Hunan Provincial Key Lab of Controllable Preparation and Functional Application of Fine Polymers, Xiangtan 411201, China

(C) Central South University Press and Springer-Verlag GmbH Germany, part of Springer Nature 2020

Erratum to: J. Cent. South Univ. (2020) 27: 1247-1261

DOI: https://doi.org/10.1007/s11771-020-4364-4

The First author's name was wrong and it should be replaced as HUANG Jing(黄晶) $)^{1,3}$.

Foundation item: Project(51778226) supported by the National Natural Science Foundation of China; Project(2018JJ3159) supported by the Hunan Provincial Natural Science Foundation for Youths, China

Received date: 2019-04-01; Accepted date: 2020-02-14

Corresponding author: LIU Qing-quan, PhD, Professor; Tel: +86-731-58290782; E-mail:qqliu@hnust.edu.cn; ORCID: 0000-0003-38464268

The online version of the original article can be found at https://oi.org/10.1007/s11771-020-4364-4 